\title{
Have Consumers Benefited from the Reforms in the Electricity Distribution Sector in Latin America? ${ }^{1}$
}

\author{
Antonio Estache \\ World Bank and ECARES, Université Libre de Bruxelles \\ Martin Rossi \\ Department of Economics, University of Oxford
}

\begin{abstract}
This paper brings new empirical evidence on the impact of the choice of ownership and regulatory regime on firms' productivity and prices paid by consumers. The evidence is collected from a sample of electricity distribution companies in Latin-America. For efficiency, we rely on estimations of a parametric labor and operation and maintenance $(\mathrm{O} \& \mathrm{M})$ input requirement functions using alternative. We then analyze the correlation between prices and productivity changes. The main conclusions of the paper are: a) private firms perform better (approximately 30\%) than public firms; b) the regulatory regimes matter; c) private firms operating under rate of return are at most as efficient as public firms; d) there is no clear pattern of differences in electricity prices according to the regulatory regime; and e) final prices fell in general but the drop did not match the productivity gains, implying that the operators and the state share some of the gains in the form of rents and higher tax revenue, respectively.
\end{abstract}

\footnotetext{
${ }^{1}$ We are grateful to Simon Cowan, Martin Rodriguez-Pardina, Sergio Perelman and Lourdes Trujillo for useful discussions in the preparation of this paper. Any mistake is ours.
} 
The last two decades witnessed major reforms in the organization of the electricity sector around the globe. Apart from the reduction in the fiscal costs and the increase in private financing of the sector, one of the main reform goals was to improve its efficiency. To realize these efficiency gains, in most cases and in particular in developing countries, the reforms were built around five main groups: (i) unbundling of generation, transmission, and distribution activities, (ii) privatization of the assets (for generation) or of the management of these assets (for transmission and distribution), (iii) promotion of competition in the market in generation, (iv) promotion of competition for the market in the other segments, and (v) increase in the incentive power of the residual regulation needed by switching from rate of return (cost-plus, cost of service) regulation to highincentive regulatory schemes. ${ }^{2}$

As a result of these changes in the electricity sector, in most fully or partially reformed countries, the generation segment is now competitive with a very strong presence of the private sector, while transmission companies are now largely public monopolies often separated from the other sectors. The largest diversity of service organization is found in the distribution ativity, where public and private companies coexist in many countries.

Following the global trend, the Latin American electricity market has undergone a major transformation over the past 20 years. Reform in the region started in Chile, with the privatization of major electric utilities between 1986 and 1989. Argentina followed Chile's example in 1992; shortly thereafter Bolivia, Colombia, and Peru followed suit.

\footnotetext{
${ }^{2}$ For a review of the theoretical literature on regulatory regimes, see Crew and Kleindorfer, 1986; Laffont and Tirole, 1993; Armstrong, Cowan, and Vickers, 1994; Sappington, 1994; Crew and Kleindorfer, 2002; and Vogelsang, 2002.
} 
During the second half of the 1990s, Panama, El Salvador, Guatemala, Nicaragua, Honduras, and Brazil also adopted reforms. The main missing players in the process of transforming the electricity sectors have been Costa Rica, Ecuador, Mexico, Paraguay, Uruguay, and Venezuela, although Costa Rica, Ecuador, Mexico, and Venezuela recently initiated actions toward restructuring.

Many authors have studied the impact of the reforms in the region, documenting an increase in labor productivity in all the countries where restructuring and privatization has taken place (see Rudnick, 1998; Fischer and Serra, 2000; and Rudnick and Zolezzi, 2001). The results obtained from these studies, however, rely on partial productivity ratios and focus on labor productivity. In this study we provide additional empirical evidence by using a more comprehensive labor requirement function approach to examine whether ownership type and type of regulatory regime have any systematic impact on labor productivity, labor productivity change, or both.

An important finding of our study is that there were substantial increases in labor productivity in the post-reform period (1994-2001). The current debate in the region is whether final consumers have benefited from this increase in labor productivity. As a first approach to address this issue, in this study we explore whether the increases in labor productivity have had an effect on lower prices for final consumers. To generate the evidence, we exploit a unique database described in an Appendix..

\section{Model specification of electricity distribution}

The electricity distribution model used in this paper includes a variable input (the number of employees), an exogenous capital input (the kilometres of distribution network), and three exogenous outputs (the number of final customers, the total energy 
supplied to final customers, and the service area). Table 1 lists summary statistics of the data.

Table 1: Summary statistics

\begin{tabular}{|c|c|c|c|c|c|}
\hline \multicolumn{2}{|c|}{$\begin{array}{c}\text { Inputs and Outputs } \\
(\text { Number of observations }=470)\end{array}$} & Mean & $\begin{array}{l}\text { Standard } \\
\text { deviation }\end{array}$ & Maximum & Minimum \\
\hline \multicolumn{2}{|c|}{ Number of employees } & 1953 & 5209 & 41063 & 88 \\
\hline \multicolumn{2}{|c|}{ Sales (in GWh) } & 6883 & 20383 & 175498 & 58 \\
\hline \multicolumn{2}{|c|}{ Number of customers } & 868194 & 2296233 & 19760000 & 21368 \\
\hline \multicolumn{2}{|c|}{ Service area (in $\left.\mathrm{km}^{2}\right)$} & 109613 & 275024 & 1889910 & 32 \\
\hline \multicolumn{2}{|c|}{ Distribution lines (in km) } & 27778 & 78770 & 595170 & 105 \\
\hline \multicolumn{2}{|c|}{ Private firms dummy } & 0.44 & 0.50 & 1 & 0 \\
\hline \multicolumn{2}{|c|}{$\begin{array}{c}\text { O\&M expenses }(\mathrm{PPP}) \\
(\text { Number of observations }=190)\end{array}$} & 157881 & 259300 & 1833086 & 695 \\
\hline \multicolumn{6}{|c|}{ Sample distribution of firms by country and ownership category } \\
\hline \multicolumn{2}{|r|}{$\begin{array}{l}\text { Number of } \\
\text { firms }\end{array}$} & Private firms & $\begin{array}{l}\text { Firms changing } \\
\text { ownership }\end{array}$ & $\begin{array}{c}\text { Number of } \\
\text { observations }\end{array}$ & $\begin{array}{l}\text { Observations } \\
\text { corresponding } \\
\text { to private firms }\end{array}$ \\
\hline Argentina & 22 & 12 & 5 & 117 & 70 \\
\hline Bolivia & 2 & 1 & 0 & 12 & 7 \\
\hline Brazil & 37 & 16 & 0 & 113 & 44 \\
\hline Chile & 2 & 2 & 0 & 14 & 14 \\
\hline Colombia & 5 & 1 & 0 & 17 & 2 \\
\hline Costa Rica & 3 & 0 & 0 & 21 & 0 \\
\hline Ecuador & 12 & 2 & 1 & 40 & 8 \\
\hline El Salvador & 4 & 4 & 0 & 12 & 12 \\
\hline Mexico & 1 & 0 & 0 & 8 & 0 \\
\hline Panama & 1 & 1 & 0 & 1 & 1 \\
\hline Paraguay & 1 & 0 & 0 & 7 & 0 \\
\hline Peru & 11 & 1 & 7 & 64 & 24 \\
\hline Uruguay & 1 & 0 & 0 & 8 & 0 \\
\hline Venezuela & 8 & 5 & 0 & 36 & 23 \\
\hline Total & 110 & 45 & 13 & 470 & 205 \\
\hline \multicolumn{6}{|c|}{ Sample distribution of firms ordered by number of employees } \\
\hline $\begin{array}{l}\text { Number of } \\
\text { employees }\end{array}$ & $\begin{array}{l}\text { Number of } \\
\text { firms }\end{array}$ & Private firms & $\begin{array}{l}\text { Firms changing } \\
\text { ownership }\end{array}$ & $\begin{array}{l}\text { Number of } \\
\text { observations }\end{array}$ & $\begin{array}{l}\text { Observations } \\
\text { corresponding } \\
\text { to private firms }\end{array}$ \\
\hline $88-400$ & 41 & 14 & 8 & 178 & 76 \\
\hline $401-1000$ & 36 & 12 & 5 & 142 & 68 \\
\hline $1001-41063$ & 33 & 19 & 0 & 150 & 61 \\
\hline
\end{tabular}

A pattern observed in Table 1 is that most of the firms changing ownership are relative small firms from Argentina and Peru. The sample distribution of firms ordered by number of employees indicates that both the number of firms and the number of observations are similarly distributed in the different size categories. The same applies to 
the number of private firms and to the number of observations corresponding to private firms.

As observed by Kumbhakar and Hjalmarsson (1998), while productivity in electricity generation is mainly determined by the technology, productivity in distribution is, to a large extent, driven by management and efficient labor use; ${ }^{3}$ accordingly, the baseline model focuses on labor productivity, and the electricity distribution technology is represented by means of a labor requirement function.

In order to estimate a parametric labor requirement function, we use a translog functional form because it provides a good second-order approximation to a broad class of functions. A translog labor requirement function with three outputs and one exogenous capital input, for a panel of $i=1, \ldots, N$ producers observed over $t=1, \ldots, T$ periods may be specified as

$$
l^{i t}=\beta+\sum_{k=1}^{4} \beta_{k} y_{k}^{i t}+\frac{1}{2} \sum_{k=1}^{4} \sum_{n=1}^{4} \beta_{k n} y_{k}^{i t} y_{n}^{i t}+\beta_{t} t+\alpha_{P R} D_{P R}^{i t}+v^{i t}
$$

where $l, y_{1}, y_{2}, y_{3}$, and $y_{4}$ are the natural logarithms of labor, sales, customers, area, and distribution lines, $D_{P R}$ is an indicator variable equal to one if the firm is private, and $v$ is the random error term. The model includes a time trend in order to allow for technical change. ${ }^{4}$

\section{Empirical results}

Ordinary least squares (OLS) estimates of the labor requirement function model are reported in Table 2. As usual for translog function approximations, outputs and the

\footnotetext{
${ }^{3}$ Typically, the labor cost share in generation amounts to less than $10 \%$ while in distribution the figure is around $50 \%$ (net of electricity generation and national grid transmission costs).

${ }^{4}$ For simplicity, we assume a neutral (and linear) technical change specification. The empirical results were unchanged when a non-neutral technical change specification was estimated.
} 
capital input have been mean corrected; therefore, the first-order output coefficients are elasticities evaluated at the sample mean.

Table 2: Estimates of labor requirement function

\begin{tabular}{|c|c|c|c|c|c|}
\hline Variable & \multicolumn{5}{|c|}{ Dependent variable: number of employees, in logs } \\
\hline \multirow[t]{2}{*}{ Intercept } & 0.513 & 0.174 & 1.645 & 1.616 & 1.432 \\
\hline & $(8.83)$ & $(0.33)$ & $(1.23)$ & $(1.20)$ & $(1.18)$ \\
\hline \multirow[t]{2}{*}{ Ln (Sales) } & 0.375 & 0.365 & 0.253 & 0.253 & 0.322 \\
\hline & $(9.21)$ & $(8.43)$ & $(5.19)$ & $(5.17)$ & $(6.88)$ \\
\hline \multirow[t]{2}{*}{ Ln (Customers) } & 0.337 & 0.350 & 0.535 & 0.538 & 0.426 \\
\hline & $(4.61)$ & $(4.70)$ & (7.14) & $(7.19)$ & $(5.71)$ \\
\hline \multirow[t]{2}{*}{ Ln (Service area) } & 0.112 & 0.109 & 0.078 & 0.084 & 0.091 \\
\hline & $(7.05)$ & $(6.71)$ & $(4.45)$ & $(4.48)$ & $(5.56)$ \\
\hline \multirow[t]{2}{*}{ Ln (Distribution network) } & -0.013 & -0.014 & -0.022 & -0.028 & -0.005 \\
\hline & $(-0.27)$ & $(-0.28)$ & $(-0.45)$ & $(-0.57)$ & $(-0.12)$ \\
\hline \multirow[t]{2}{*}{ Time } & -0.076 & -0.077 & -0.058 & -0.051 & -0.060 \\
\hline & $(-8.18)$ & $(-8.08)$ & $(-5.77)$ & $(-4.00)$ & $(-6.53)$ \\
\hline \multirow[t]{2}{*}{ Time*Private firms dummy } & & & & -0.017 & \\
\hline & & & & $(-0.95)$ & \\
\hline \multirow{2}{*}{ Ln (GNP per capita) } & & 0.039 & -0.142 & -0.140 & -0.109 \\
\hline & & $(0.64)$ & $(-0.88)$ & $(-0.85)$ & $(-0.73)$ \\
\hline \multirow[t]{2}{*}{ Private firms dummy } & -0.305 & -0.311 & -0.410 & -0.323 & -0.405 \\
\hline & $(-6.46)$ & $(-6.22)$ & $(-8.03)$ & $(-3.17)$ & $(-8.32)$ \\
\hline Country dummies $^{\dagger}$ & No & No & Yes & Yes & Yes \\
\hline Log likelihood & -249.92 & -249.73 & -180.00 & -179.49 & -133.11 \\
\hline R-squared & 0.89 & 0.89 & 0.92 & 0.92 & 0.93 \\
\hline Number of firms & 110 & 110 & 110 & 110 & 108 \\
\hline Observations & 470 & 470 & 470 & 470 & 451 \\
\hline
\end{tabular}

Notes: t-ratios obtained by using heteroskedasticity-consistent standard errors are in parentheses. In all cases we are estimating a translog form. To save space, second order terms are not shown. In all models the Cobb-Douglas specification is rejected against a translog at the $1 \%$ level.

In the model in column (5) Ln (Sales) was replaced by Ln (Sales + Network losses).

${ }^{\dagger}$ In models (3) to (5) the country dummies are significant at the $1 \%$ level.

In all models, the first-order output coefficients are significant at the usual levels of confidence and have the expected signs regarding economic behaviour-an increase in outputs is associated with an increase in the use of labor. The coefficient on kilometres of distribution network is never significant. The values of the estimated coefficients suggest that labor use is mainly driven by the electricity sold and the number of customers.

The coefficient of the time trend is negative and significant at the $1 \%$ level in all six models; the average rate of labor productivity growth is in the range of $5.1 \%$ to $7.7 \%$, 
numbers that are consistent with previous findings in the specialized literature (see Rudnick, 1998; Fischer and Serra, 2000; and Rudnick and Zolezzi, 2001). In all cases we test the null hypothesis of a Cobb-Douglas specification against the more general translog using the likelihood ratio (LR) statistic and we are able to reject the null at the $1 \%$ level. Overall, estimates regarding technological parameters are in line with the specialized literature on electricity distribution, yielding further confidence to the validity of the estimation strategy.

In the baseline model in column (1), the coefficient of the dummy corresponding to private firms is negative and significant at the $1 \%$ level, suggesting that private firms are more labor efficient than their public counterparts. The coefficient is also significant in economic terms: private firms use about $30 \%$ less labor to produce a given bundle of outputs than public firms.

In order to avoid possible omitted variable biases, we extend the baseline model by including GNP per capita. As reported in column (2), GNP per capita is not significant at any of the usual levels of confidence. Besides, the addition of GNP per capita to the model appears not to have any effect on the sign, values, and significance of other coefficients.

Even after controlling for GNP per capita, it might be still argued that the estimates are biased as the ownership effect is confounded with all the other country-level differences which affect firm performance. In order to control for potential biases caused by any omitted variable that is country specific and time invariant we include country fixed-effects. Results corresponding to the specification with country dummies are reported in column (3) of Table 2 . The coefficient on the private dummy is still negative 
and significant at the $1 \%$ level giving further confidence to the conclusion that private firms are more efficient than public firms.

In order to explore the possibility that technical change differs by ownership type we add the interaction between the time trend and the private ownership dummy variable to the model in (3). As shown in column (4) the interaction variable is not significant at the usual levels of confidence, suggesting a common time trend for public and private firms.

We also present a model controlling by network losses-i.e., the energy that is lost in the distribution activity. ${ }^{5}$ As pointed out by Bagdadioglu, Waddams Price, and Weyman-Jones (1996), network losses reflect the quality of the network system in terms of how much power was lost in the transformers and during distribution, and how much power was uncounted for other reasons, such as illegal use. Technical losses are strictly related to the square of the distance transmitted, and hence the baseline model captures them. The main concern is related to non-technical losses; if public firms face-or are willing to accept-higher illegal use, they will appear as inefficient because part of their inputs are used in the distribution of energy that is not captured by the "sales" variable used in the previous specifications. In order to address if not including network losses has any impact on the estimated coefficients, we reproduce the baseline model but replacing "sales" by "sales + energy losses". As shown in column (5), the coefficient on the private dummy is still negative and significant at the $1 \%$ level.

Finally, the results were unchanged when we computed clustered standard errors by firm or country-year combinations. We also estimated an alternative specification

\footnotetext{
${ }^{5}$ Due to lack of data on network losses for some firms, including losses in the model reduces the number of observations to 451 -instead of 470 ; the mean of network losses (in percentage of energy sold) is $16 \%$, with a standard deviation of $9 \%$.
} 
allowing non-neutral technical change-introducing interactions between the time trend and the outputs and the capital input-with similar results. We represented technical change by including time fixed-effects instead of a time trend and we also obtained similar results. ${ }^{6}$

\section{Assessing the robustness of the results}

To further address the validity of the results we estimate four alternative specifications: (1) stochastic frontier model; (2) between-firms variations model; (3) model in first differences; and (4) operating and maintenance expenditures model.

\section{Stochastic frontier model}

The relative efficiency of firms in the OLS model is based on the assumption that all firms in a particular ownership group are equally efficient. Such a restrictive assumption is relaxed in the following stochastic frontier model. Stochastic frontier models - first developed by Aigner, Lovell, and Schmidt (1977) and Meeusen and van de Broeck (1977) — differ from OLS by the inclusion, aside from the usual symmetric error reflecting noise, of a second error term reflecting inefficiency. The stochastic frontier model is specified as

$$
l^{i t}=\beta+\sum_{k=1}^{4} \beta_{k} y_{k}^{i t}+\frac{1}{2} \sum_{k=1}^{4} \sum_{n=1}^{4} \beta_{k n} y_{k}^{i t} y_{n}^{i t}+\beta_{t} t+\varepsilon^{i t} .
$$

The composite error term $\varepsilon^{i t}=v^{i t}+u^{i t}$ allows for inefficiency in production $\left(u^{i t}\right)$ and for noise $\left(v^{i t}\right)$. The labor requirement frontier is given by equation (1) when $u=0$. Thus, the frontier gives the minimum amount of labor required to produce a given level of outputs. The noise term is assumed to be independent and identically distributed

\footnotetext{
${ }^{6}$ All results reported but not presented are available from the authors upon request.
} 
$N\left(0, \sigma_{v}^{2}\right)$. All $v^{\prime} s$ and $u^{\prime} s$ are assumed to be independent of each other and of the regressors. The $u^{i t} s$ are non-negative random variables assumed to be independently distributed such that $u^{i t}$ is the truncation (at zero) of the normal distribution with mean $\mu^{i t}$ and variance $\sigma_{u}^{2}$. The mean $\mu^{i t}$ is further specified as

$$
\mu^{i t}=\lambda_{0}+\lambda_{P R} D_{P R}^{i t}
$$

The parameter $\lambda_{P R}$ measures the effect that private ownership has on the mean of the distribution of the inefficiency term prior to truncation. If $\lambda_{P R}<0$, then inefficiency is reduced because, on average, private firms use fewer employees than public firms to produce an equal amount of outputs. ${ }^{7}$

Maximum likelihood (ML) estimates of the stochastic labor requirement frontier are reported in column (1) of Table $3 .^{8}$ To derive the likelihood function, we use the parameterization proposed by Battese and Corra (1977): $\gamma=\sigma_{u}^{2} /\left(\sigma_{v}^{2}+\sigma_{u}^{2}\right)$. The parameter $\gamma$ must lie between zero and one, where zero indicates that the deviations from the frontier are due entirely to noise-the OLS assumption.

\section{Table 3: Alternative specifications}

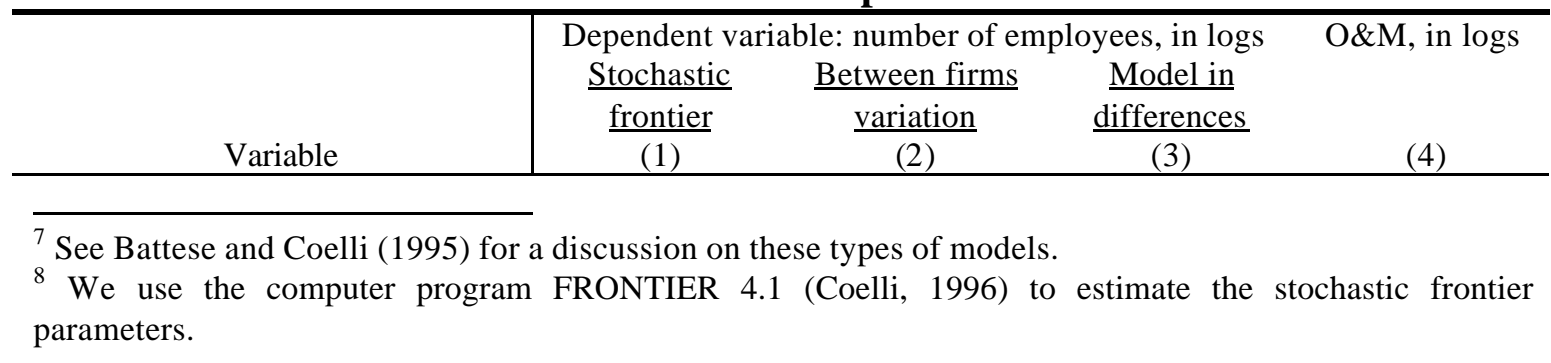




\begin{tabular}{|c|c|c|c|c|}
\hline \multirow[t]{2}{*}{ Intercept } & 1.380 & 2.008 & & 4.235 \\
\hline & $(1.05)$ & $(1.45)$ & & $(1.37)$ \\
\hline \multirow[t]{2}{*}{ Ln (Sales) } & 0.255 & 0.217 & 0.252 & 0.818 \\
\hline & $(8.25)$ & $(4.01)$ & $(2.37)$ & $(5.28)$ \\
\hline \multirow[t]{2}{*}{ Ln (Customers) } & 0.538 & 0.577 & 0.238 & 0.227 \\
\hline & $(8.76)$ & $(6.72)$ & $(1.55)$ & $(1.07)$ \\
\hline \multirow[t]{2}{*}{ Ln (Service area) } & 0.079 & 0.097 & 0.133 & 0.092 \\
\hline & $(7.82)$ & $(5.35)$ & $(1.05)$ & $(2.37)$ \\
\hline \multirow[t]{2}{*}{ Ln (Distribution network) } & -0.027 & -0.035 & -0.002 & -0.143 \\
\hline & $(-0.87)$ & $(-0.71)$ & $(-0.03)$ & $(-1.89)$ \\
\hline \multirow[t]{2}{*}{ Time } & -0.059 & -0.066 & -0.043 & 0.007 \\
\hline & $(-6.30)$ & $(-6.45)$ & $(-4.15)$ & $(0.25)$ \\
\hline \multirow[t]{2}{*}{ Time*Private firms dummy } & & & -0.015 & \\
\hline & & & $(-1.19)$ & \\
\hline \multirow[t]{2}{*}{ Ln (GNP per capita) } & -0.160 & -0.179 & -0.060 & 0.732 \\
\hline & $(-1.00)$ & $(-1.07)$ & $(-0.96)$ & $(2.18)$ \\
\hline \multirow[t]{2}{*}{ Private firms dummy } & -1.299 & -0.460 & -0.224 & -0.050 \\
\hline & $(-13.54)$ & $(-8.07)$ & $(-2.34)$ & $(-0.28)$ \\
\hline Intercept (stochastic frontier only) & $\begin{array}{c}0.435 \\
(31.34)\end{array}$ & & & \\
\hline \multirow[t]{2}{*}{ Stochastic frontier parameter $(\gamma)$} & 0.124 & & & \\
\hline & $(42.12)$ & & & \\
\hline Country dummies ${ }^{\dagger}$ & Yes & Yes & No & Yes \\
\hline Log likelihood & -141.98 & -140.72 & 244.62 & -159.30 \\
\hline R-squared & & 0.93 & 0.24 & 0.88 \\
\hline Number of firms & 110 & 97 & 104 & 72 \\
\hline Observations & 470 & 399 & 350 & 190 \\
\hline
\end{tabular}

Notes: t-ratios obtained from heteroskedasticity-consistent standard errors are in parentheses, except for the stochastic frontier specification. In all cases we are estimating a translog form. To save space, second order terms are not shown. In models (1), (2), and (4) the Cobb-Douglas specification is rejected against a translog at the $1 \%$ level. In model (3) it is rejected at the $13 \%$ level.

${ }^{\dagger}$ In models (1), (2), and (4) the country dummies are significant at the $1 \%$ level.

The stochastic frontier estimates for the labor requirement frontier are similar to those of the OLS model except for the intercept, which appears to be biased upwards. This is in accordance with previous expectations because OLS yields consistent estimates of all parameters of the frontier model but the intercept.

The estimated coefficients in the inefficiency model are of particular interest to this study. ${ }^{9}$ The coefficient on the private dummy is negative and significant at the $1 \%$ level,

\footnotetext{
${ }^{9}$ The null hypothesis, $H_{0}: \gamma=\lambda_{0}=\lambda_{P R}=0$, which specifies that inefficiency effects are absent from the model, is rejected at the $1 \%$ level: the likelihood ratio test on the one-sided error is equal to 160.06 , which is greater than 10.50, the critical value for three degrees of freedom obtained from Kodde and Palm (1986).
} 
a result similar to those reported in previous specifications. Thus, private firms appear to use fewer employees, ceteris paribus, than public firms. The value of the coefficients suggests that the modal private firm operates efficiently and that the modal public firm operates inefficiently, in the sense of using more employees to produce a given vector of outputs.

\section{Between-firms variations}

The between-firms variations model uses a subset of firms consisting of those that have constant ownership type. Such a sub-sample guarantees that the dummy variable accounts only for between-firm variations in ownership, which are more likely to capture a long-run effect of ownership type on efficiency.

OLS estimates of the between-firms variations model are reported in column (2) of Table 3. The results are similar to those in the full sample case: the coefficient on the private dummy is negative and significant at the $1 \%$ level, suggesting that private firms are more efficient in the use of labor than their public counterparts.

\section{Model in first differences}

The previous specifications established a positive correlation between private ownership and firm-level efficiency. In the early stage of the reforms, however, governments may wish to demonstrate that privatized firms achieve higher efficiency. To do so they are likely to choose to privatize firms that are already operating relatively efficiently, so that when privatized they provide an example of high efficiency compared with their remaining public sector counterparts. This would imply that the preceding results might be biased in favour of finding that private ownership improves efficiency. If

The hypothesis that inefficiency effects are not stochastic, $H_{0}: \gamma=0$, is also rejected at the $1 \%$ level $(\mathrm{LR}=76.05>8.27)$. 
governments decide privatizations as a response to prior efficient production, one may still ask how changes in ownership status affect efficiency for a given firm-i.e., whether changes in ownership are associated with changes in labor productivity-without the same endogeneity concern (because any permanent influences on the level of efficiency have been "differenced" out). ${ }^{10}$

We start with the general model presented in column (4) of Table 2:

$l^{i t}=\beta+\beta_{C} D_{C}+\sum_{k=1}^{4} \beta_{k} y_{k}^{i t}+\frac{1}{2} \sum_{k=1}^{4} \sum_{n=1}^{4} \beta_{k n} y_{k}^{i t} y_{n}^{i t}+\beta_{t} t+\beta_{t^{*} P R}\left(t * D_{P R}^{i t}\right)+\beta_{P R} D_{P R}^{i t}+\beta_{G N P} G N P^{i t}+v^{i t}$, where $D_{C}$ are country fixed-effects and GNP is the natural logarithm of GNP per capita.

Differencing the above equation gives

$$
\Delta l^{i t}=\sum_{k=1}^{4} \beta_{k} \Delta y_{k}^{i t}+\frac{1}{2} \sum_{k=1}^{4} \sum_{n=1}^{4} \beta_{k n} \Delta\left(y_{k}^{i t} y_{n}^{i t}\right)+\beta_{t}+\beta_{t^{*} P R} D_{P R}^{i t}+\beta_{P R} \Delta D_{P R}^{i t}+\beta_{G N P} \Delta G N P^{i t}+\Delta v^{i t}
$$

Results from the specification in first differences estimated using OLS are reported in column (3) of Table 3. As in the corresponding specification in levels (shown in column (4) of Table 2), the coefficient on the interaction between the time trend and the private ownership dummy $\left(\beta_{t^{*} P R}\right)$ is not significant at the usual confidence levels. The coefficient on the time trend $\left(\beta_{t}\right)$ is negative and significant at the $1 \%$ level, and its value $(-0.04$, with a standard error equal to 0.01$)$ is not greatly different from the corresponding coefficient in the specification in levels $(-0.05$, with a standard error equal to 0.01 ), as shown in column (4) of Table 2. The coefficient on the private dummy $\left(\beta_{P R}\right)$ is negative and significant at the $2 \%$ level. Again, its value $(-0.22$, with a standard error equal to 0.09) is not greatly different from the corresponding coefficient in the

\footnotetext{
${ }^{10}$ Differencing controls for only the "level" bias. If privatizations are chosen based on expected future improvements in efficiency, there would still be a bias.
} 
specification in levels (-0.32, with a standard error equal to 0.10$)$, given the precision with which these coefficients are estimated. Thus, the estimates of the specification in differences suggest that the previous results are relatively robust to controlling for the potential endogeneity of ownership that could arise if governments privatized those utilities with the highest labor productivity first.

\section{Operating and maintenance expenditures model}

In this section we estimate an alternative model in which the dependent variable is the firms' operating and maintenance (O\&M) expenses instead of the number of employees. Using O\&M expenses as the dependent variable has the advantage of taking into account expenditures of works contracted outside the firm thus making more comparable firms with different levels of horizontal integration. For instance, labor compensation packages allowed new privatized firms to outsource labor intensive services (e.g., cleaning services), which is not an option to most state owned firms due to unions' power.

As shown in column (4) of Table 3, the coefficient of the ownership dummy variable becomes insignificant in the O\&M specification. This might reflect differences in horizontal integration levels across private and public firms. It might also be due to public firms incurring lower maintenance expenditures than private firms, because in Latin America publicly owned distribution firms generally face lower requirements of service quality. Indeed, there is substantial evidence that during the 1990s quality requirements were imposed on privatized firms, with penalties for not fulfilling those requirements. As Fischer and Serra (2000) document, fines for bad service were increased considerably at the time of privatization resulting in improvements in the 
quality of service (see also Rudnick and Zolezzi, 2001). In countries where privatization has not taken place, quality requirements have generally not improved. In Costa Rica, for example, the regulatory framework for the electricity sector does not contemplate fines to firms not delivering minimum quality levels. In Mexico, another country where the distribution activity is still public, there is "a deficient quality of service in electricity distribution", according to the President of the Mexican Regulatory Commission. ${ }^{11}$ Thus, the evidence tends to point out that the lack of data on quality of service would lead to an underestimation of the efficiency of private firms. Thus, this can perhaps explain results showing public firms being more inefficient in terms of labor use but not less efficient in terms of operational expenditures: this disparity might reflect the fact that public firms incur less maintenance expenditures because they do not need to guarantee the same quality of service.

In order to check the plausibility of the above conjecture, we take advantage of some information available for a widely used measure for quality of service: mean frequency of interruptions per customer (FC), defined as $F C=\frac{\sum_{i=1}^{n} C a_{i}}{C s}$ (where $C a_{i}$ is the number of customers affected by interruption $i, C s$ is the total number of customers, and $\mathrm{n}$ is the total number of interruptions). Table 4 presents sample summary statistics, by country, for FC.

Table 4: Summary statistics of quality of service

\begin{tabular}{ccc}
\hline & \multicolumn{3}{c}{ Mean frequency of interruption per customer (FC) } \\
\hline Country & Number of observations & Sample mean \\
\hline Argentina & 22 & 6.98 \\
Bolivia & 7 & 11.23 \\
Brazil & 113 & 21.08
\end{tabular}

\footnotetext{
${ }^{11}$ See the report presented in the Second Hemispheric Conference of Energy Regulators that can be found at http://www.iie.org/programs/energy/usdoe.
} 


\begin{tabular}{ccc} 
Chile & 0 & \\
Colombia & 6 & 9.00 \\
Ecuador & 4 & 24.63 \\
Paraguay & 0 & 17.58 \\
Uruguay & 2 & 6.42 \\
Venezuela & 6 & 22.15 \\
Peru & 4 & 15.02 \\
Costa Rica & 15 & \\
Panama & 0 & \\
Mexico & 0 & 17.62 \\
El Salvador & 0 & 19.11 \\
\hline Total & 179 & 15.41 \\
\hline Public firms & 107 &
\end{tabular}

As shown in Table 4 the average of FC for privatized firms is lower than the average for public firms, giving support to the hypothesis that the coefficient of the ownership dummy might be biased in favour of showing public firms as more efficient.

\section{Regulatory Regimes}

Privatization always involves changes in both ownership and regulation, since the alternative to state ownership is rarely purely private, unregulated firms. Further research is needed in order to separate ownership effects from type of regulation effects. In this section we address this issue by analyzing the impact of alternative regulatory regimes and ownership structures on the technical efficiency of electricity distribution firms in Latin America (for a review of the relevant theoretical literature on regulation, see Crew and Kleindorfer, 1986; Laffont and Tirole, 1993; Armstrong, Cowan, and Vickers, 1994; Sappington, 1994; and Vogelsang, 2002).

Latin America provides one of the best sources of evidence on the efficiency effects of ownership and regulatory reform in the electricity sector; during the 1990s the region was the champion for these reforms and, at the same time, it provides reasonable variation across countries in the degree of endorsement of privatization and the choices of regulatory regimes. About a third of the countries in the region adopted a price cap (PC) 
scheme and a third adopted rate of return (RoR) regulation while the last third adopted hybrid regimes (HR) in which some costs changes are automatically passed through to tariffs. This is clearly a very rough classification of regulatory regimes since the incentive for improvements in efficiency are strongly correlated with the specific design of the regime. In the case of $\mathrm{HR}$, for instance, the larger the share of costs enjoying an automatic pass-through rule, the closer the regime is to RoR regulation and hence the lower the expected incentive to minimize costs. The classification is, however, useful enough to allow an explicit modelling of the influence of broad categories of regulation on the efficiency of the operators.

\section{Data and model specification}

The baseline econometric model used to analyze the impact of alternative regulatory schemes on labor productivity is the same as the one used above. The information about type of regulatory regime was obtained from Espinasa (2001) and checked by asking regulators and governmental agencies. A classification of the type of regulatory regime in each of the countries in the sample is listed in Table A.2 (see Appendix).

The translog average labor requirement function is specified as

$$
l^{i t}=\beta+\beta_{C} D_{C}+\sum_{k=1}^{4} \beta_{k} y_{k}^{i t}+\frac{1}{2} \sum_{k=1}^{4} \sum_{n=1}^{4} \beta_{k n} y_{k}^{i t} y_{n}^{i t}+\beta t+\alpha_{R o R} D_{R o R}^{i t}+\alpha_{H R} D_{H R}^{i t}+\alpha_{P C} D_{P C}^{i t}+v^{i t}
$$

where $l, y_{1}, y_{2}, y_{3}$, and $y_{4}$ are the natural logarithms of labor, sales, customers, area, and distribution lines, $D_{j}$ is an indicator variable equal to one for private firms operating under regulatory regime $\mathrm{j}$ (see Table 5 for their descriptions), $t$ is the time trend, and $v$ is the random error term. 
Table 5: Definition of dummy variables

\begin{tabular}{c|lc}
\hline Variable & \multicolumn{1}{|c}{ Description } & Number of observations \\
\hline$D_{P C}$ & $\begin{array}{l}\text { Equal to } 1 \text { if the firm is private and operates under a price cap } \\
\text { scheme }\end{array}$ & 117 \\
$D_{H}$ & $\begin{array}{l}\text { Equal to } 1 \text { if the firm is private and operates under an hybrid } \\
\text { scheme }\end{array}$ & 65 \\
$D_{R o R}$ & $\begin{array}{l}\text { Equal to } 1 \text { if the firm is private and operates under a rate of } \\
\text { return scheme } \\
\text { Public firms (default category) }\end{array}$ & 23 \\
\hline
\end{tabular}

\section{Results}

OLS estimates of the labor requirement function are reported in column (1) of Table

6. To avoid possible omitted variable biases, we include GNP per capita and country fixed effects as controls. As usual for translog function approximations, outputs have been mean corrected.

In the two models presented in Table 6, the first-order output coefficients are significant at the $1 \%$ level and have the expected signs regarding economic behaviouran increase in output is associated with an increase in the use of labor. The coefficient on kilometres of distribution network is not significant. The coefficient of the time trend is negative and significant at the $1 \%$ level; the average rate of labor productivity growth is in the range of $5.5 \%$ to $6 \%$.

The coefficient on RoR is positive but not significant, indicating that private firms operating under RoR are not significantly different from public firms in terms of their efficiency levels. The PC and HR dummies are negative and significant at the $1 \%$ level. They are also significantly different from each other, suggesting that private firms operating under PC are the most efficient in this sample. These coefficients are also significant in economic terms: private firms operating under PC and hybrid schemes use, respectively, about $55 \%$ and $25 \%$ less labor to produce a given bundle of output, given the capital input, than public firms and private firms under RoR. 
Table 6: Estimates of labor requirement function

\begin{tabular}{c|cc}
\hline & \multicolumn{2}{|c}{ Dependent variable: number of employees, in logs } \\
Variable & $(1)$ & $(2)$ \\
\hline Intercept & 1.392 & 1.109 \\
& $(1.03)$ & $0.77)$ \\
Ln (Sales) & 0.210 & 0.206 \\
Ln (Customers) & $(3.89)$ & $(3.71)$ \\
& 0.619 & 0.627 \\
Ln (Service area) & $(7.53)$ & $(7.45)$ \\
& 0.097 & 0.099 \\
Ln (Distribution network) & $(5.41)$ & $(5.11)$ \\
Time & -0.064 & -0.069 \\
& $(-1.27)$ & $(-1.35)$ \\
Time* Rate of return dummy variable & -0.055 & -0.057 \\
Time* Hybrid regimes dummy variable & $(-5.42)$ & $(-4.31)$ \\
& & 0.067 \\
Time* Price cap dummy variable & & $(1.29)$ \\
& & -0.008 \\
Ln (GNP per capita) & & $-0.41)$ \\
& & -0.002 \\
Rate of return dummy variable & -0.133 & $(-0.08)$ \\
& $(-0.81)$ & -0.096 \\
Hybrid regimes dummy variable & 0.009 & $(-0.55)$ \\
& $(0.06)$ & -0.184 \\
Price cap dummy variable & -0.270 & $(-0.75)$ \\
& $(-3.95)$ & -0.233 \\
Country dummies & & $(-2.56)$ \\
Log likelihood & -0.538 & -0.529 \\
Number of firms & $(-7.52)$ & $(-3.31)$ \\
\hline Observations & Yes & Yes \\
& -171.99 & -170.93 \\
& 0.92 & 0.92 \\
& 110 & 110 \\
& 470 & 470 \\
\hline
\end{tabular}

Notes: t-ratios obtained by using heteroskedasticity-consistent standard errors are in parentheses. In all cases we are estimating a translog form. To save space, second order terms are not shown. In all models the CobbDouglas specification is rejected against a translog at the $1 \%$ level.

${ }^{\dagger}$ In all models the country dummies are significant at the $1 \%$ level.

In order to explore the possibility that technical change differs by type of regulatory regime, we add the interaction between the time trend and the regulatory regime dummy variables to the model in column (1) of Table 6. As shown in column (2) the interaction variables are individually and jointly not significant at the usual confidence levels, suggesting a common time trend for all firms in the sample. 
Overall, results indicate that there is no significant difference in efficiency between public firms and private firms operating under a RoR regime. Firms operating under a PC regime are the most efficient, whereas those operating under HR are in between .

\section{The impact of the reforms on electricity prices}

Table 7 lists average household and industrial KWh electricity prices by country, both with taxes and without taxes, along with the share of private sector participation in the distribution activity and the type of regulatory regime under which firms' operate. ${ }^{12}$

Table 7: Average electricity prices by country

\begin{tabular}{ccc|cccc}
\hline & $\begin{array}{c}\text { Private sector } \\
\text { participation } \\
\text { in distribution }\end{array}$ & $\begin{array}{c}\text { Regulatory } \\
\text { regime }\end{array}$ & \multicolumn{3}{|c}{ Prices corresponding to the year 2001 } \\
Country & (in \%) & & \multicolumn{2}{|c}{ With taxes } & Without taxes \\
\hline Argentina & 70 & Price cap & 13.50 & 10.94 & 10.79 & 8.07 \\
Bolivia & 90 & Hybrid & 14.90 & 14.02 & 10.02 & 9.67 \\
Brazil & 60 & Price cap & 21.47 & 9.84 & 17.64 & 8.07 \\
Chile & 90 & Hybrid & 16.07 & 10.30 & 13.64 & 8.73 \\
Colombia & 50 & Price cap & 23.10 & 15.07 & 6.79 & 12.33 \\
Costa Rica & 10 & Rate of return & 15.04 & 17.75 & & \\
Ecuador & 20 & Hybrid & 16.28 & 18.94 & & \\
El Salvador & 40 & Hybrid & 33.84 & 38.75 & & \\
Mexico & 10 & Rate of return & 11.12 & 7.71 & & \\
Panama & 100 & Price cap & 20.16 & 16.52 & 20.16 & 16.52 \\
Paraguay & 0 & Rate of return & 24.13 & 13.80 & 22.02 & 12.62 \\
Peru & 60 & Hybrid & 22.58 & 12.87 & 22.56 & 12.93 \\
Uruguay & 0 & Rate of return & 18.81 & 9.58 & 15.32 & 7.52 \\
Venezuela & 20 & Rate of return & 6.46 & 3.29 & & 2.06 \\
\hline
\end{tabular}

Notes: All prices are at the country level, and correspond to the year 2001, except for prices without taxes in Colombia, which correspond to the year 2000 and were converted into 2001 price levels by using the US Consumer Price Index.

Regulatory regimes and the share of private sector participation in the distribution activity for all countries but Panama, were obtained from Espinasa (2001). The share of private sector participation in the distribution activity for Panama was obtained from the regulator of the public services in that country.

In order to harmonize electricity prices across countries, all prices are in 2001 US dollars per KWh of electricity and are expressed in terms of purchasing power parity.

The simple correlations between the share of private sector participation in the distribution activity and household prices with taxes, industrial prices with taxes, household prices without taxes, and industrial prices without taxes (all corresponding to

\footnotetext{
${ }^{12}$ The data is from the OLADE data base which only reflects taxes as reported by governments and usually tend to ignore subnational taxes which in some countries may bias the analysis.
} 
the year 2001) are $0.07,0.04,-0.23$, and 0.36 , respectively. This indicates that electricity prices at the household or industrial level, with taxes or without taxes, are not highly correlated with ownership.

The following table shows the average 2001 prices by type of regulatory regime.

Table 8: Average electricity prices across countries by type of regulatory regime

\begin{tabular}{|c|c|c|c|c|}
\hline \multirow[b]{3}{*}{$\begin{array}{l}\text { Type of regulatory } \\
\text { regime }\end{array}$} & \multicolumn{4}{|c|}{ Average prices corresponding to the year 2001} \\
\hline & \multicolumn{2}{|c|}{ With taxes } & \multicolumn{2}{|c|}{ Without taxes } \\
\hline & Household & Industrial & Household & Industrial \\
\hline Price cap & 19.6 & 13.1 & 13.8 & 11.2 \\
\hline Hybrid & 20.7 & 19.0 & 15.4 & 10.4 \\
\hline Rate of return & 15.1 & 10.4 & 18.7 & 7.4 \\
\hline
\end{tabular}

An inspection of Table 8 suggests that there is not a clear pattern of differences in electricity prices according to type of regulatory regime. This is to be expected since prices are on average driven by the basic technology (\% of hydro vs. $\%$ of termal) and regulation and taxes only influence prices at the margin.

\section{Price changes vs. labor productivity changes}

As shown in Tables 2 and 6, the average annual rate of labor productivity change for the period 1994-2001 has been about 6\%. The current debate in the Region is whether final consumers have benefited from this increase in labor productivity. As a first approach to address this issue, in this section we explore whether the increases in labor productivity have had an effect on lower prices for final consumers.

Table 9 lists the average annual rate of change (over the period 1994-2001) in household and industrial electricity prices by country, along with the average annual rate of labor productivity change. The countries' average rate of labor productivity change was obtained by adding the interaction between the time trend and the country dummies to the model in column (1) of Table 6. Similar conclusions are reached when the 
interactions between the time trend and the country dummies are added to the model in column (3) of Table 2. Table 9 shows that the coefficients on labor productivity change are negative-i.e. an increase in labor productivity over time-for all countries but Venezuela, the only country where private firms operate under a RoR scheme.

A comparison of the changes in prices and labor productivity reveals that, in most cases, final prices to customers did not fall to reflect the huge labor productivity gains that were achieved during the period under analysis.

It should not be concluded, however, that the results presented above provide conclusive evidence that consumers have not benefited from the reform process in the region. As pointed out by Kridel, Sappington, and Weisman (1996), low service rates is just one of many possible benefits from incentive regulation schemes. There is evidence, for instance, that quality of service has improved more in those countries under highincentive regimes (see the discussion above). Besides that, in most of the countries where privatization has taken place, by 2001 no price reviews have taken place. This is important given that price cap is known to have an impact on prices only after at least one price review. Finally, the final price faced by households and industrial customers is influenced not only by the efficiency in the distribution activity, but also by the generation and transmission stages. That is, both further research and a longer time period after the privatization are needed before general conclusions on whether final customers have benefited from the privatization process in the electricity sector can be made.

Table 9: Price changes vs. labor productivity changes

\begin{tabular}{|c|c|c|c|c|c|c|c|c|c|c|}
\hline \multirow[b]{3}{*}{ Country } & \multirow{2}{*}{\multicolumn{5}{|c|}{$\begin{array}{c}\text { Number of observations in the sample } \\
\text { Regulated by }\end{array}$}} & \multicolumn{5}{|c|}{ Annual rate of change } \\
\hline & & & & & & \multicolumn{2}{|c|}{ Prices with taxes } & \multicolumn{2}{|c|}{ Prices without taxes } & \multirow[t]{2}{*}{ LP } \\
\hline & Total & Private & $\mathrm{PC}$ & $\mathrm{HR}$ & RoR & $\mathrm{H}$ & $\mathrm{I}$ & $\mathrm{H}$ & $\mathrm{I}$ & \\
\hline Argentina & 117 & 70 & 70 & 0 & 0 & 0.010 & 0.014 & -0.02 & 0.01 & -0.046 \\
\hline
\end{tabular}




\begin{tabular}{c|ccccc|ccccc}
\hline Bolivia & 12 & 7 & 0 & 7 & 0 & -0.083 & -0.091 & -0.10 & -0.11 & $\begin{array}{c}(-2.29) \\
-0.003 \\
(-0.08) \\
\text { Brazil }\end{array}$ \\
\hline Chile & 113 & 44 & 44 & 0 & 0 & 0.032 & -0.010 & 0.04 & 0.01 & $\begin{array}{c}-0.091 \\
(-3.79)\end{array}$ \\
Colombia & 14 & 14 & 0 & 14 & 0 & -0.118 & -0.102 & -0.11 & -0.10 & -0.061 \\
$(-5.90)$ \\
Costa
\end{tabular}

Notes: t-ratios obtained from heteroskedasticity-consistent standard errors are in parentheses.

$\mathrm{PC}=$ price cap; $\mathrm{HR}=$ hybrid regimes; $\mathrm{RoR}=$ rate of return; $\mathrm{H}=$ household prices; $\mathrm{I}=$ industrial prices; $\mathrm{LP}$ $=$ labor productivity.

Panama was excluded from the analysis since there is data for only one period.

All KWh of electricity prices were converted into 2001 price levels using the US Consumer Price Index and expressed in terms of purchasing power parity.

\section{Concluding remarks}

In this study we compare the relative performance of public and privatized Latin American electricity distribution utilities for the years 1994 to 2001. The labor productivity analysis gives the following main conclusions: (i) privatized firms are more labor efficient than their public counterparts; and (ii) there is evidence of labor productivity growth during the period. The results are significant in economic termsprivate firms use about $30 \%$ to $45 \%$ less labor to produce a given bundle of outputs than public firms, and they are relatively robust to controlling for the potential endogeniety of ownership that could arise if governments privatized those utilities with the highest labor productivity first. 
We also analyze the impact of alternative regulatory regimes on efficiency. The ideal environment in which to measure the impact of different types of regulatory schemes is one in which all factors other than the regulatory regime itself are held constant. This was not the environment in which regulatory regimes were introduced in Latin America, since high-incentive regulation was introduced at the moment of privatization. Besides, the goals of regulators, the laws behind the reform processes, and relevant histories all vary across countries. Therefore, empirical findings regarding the impact of different regulatory regimes on efficiency must be interpreted with great care.

Taking the above caveat in mind, labor productivity analysis provides the following main results: (i) that private firms operating under price cap and hybrid schemes are more labor efficient than both public firms and private firms under rate of return regulation; (ii) that firms regulated under hybrid regimes have intermediate efficiency levels; and (iii) that private firms operating under rate of return regulation have, at most, similar labor efficiency as public firms. Result (i) and (ii) are consistent with the prediction from theory and with the findings of similar studies conducted for electricity distribution and other sectors.

Overall, the empirical evidence presented here does not provide definitive conclusions about the effects of privatization and incentive regulation on the efficiency of electricity distribution firms in Latin America in the period 1994-2001 since some important variables are missing from the analysis. For similar reasons, the evidence is also only partial on whether final customers have been benefited from the sector's reforms but it does suggest that price changes from the viewpoint of users and efficiency gains are not as correlated as expected. The difference between users price and efficiency 
changes is shared between operators and government in the form of rents and additional tax revenue respectively. Additional research, which includes the collection of comparable data on service quality and a longer period of analysis, is however required to refine the assessment. 


\section{References}

Aigner, D., C.A. Knox Lovell, and P. Schmidt (1977). "Formulation and Estimation of Stochastic Frontier Production Function Models." Journal of Econometrics 6 (1), 2127.

Armstrong, M., S. Cowan and J. Vickers (1994). Regulatory Reform. Economic Analysis and British Experience. Cambridge, Massachusetts: The MIT Press.

Bagdadiouglu, N., C. Waddams Price, and T. Weyman-Jones (1996). "Efficiency and Ownership in Electricity Distribution: A Non-Parametric Model of the Turkish Experience.” Energy Economics 18 (1-2), 1-23.

Battese, G. and G. Corra (1977). "Estimation of a Production Frontier Model: With Application to the Pastoral Zone of Eastern Australia." Australian Journal of Agricultural Economics 21 (3), 169-179.

Battese, G. and T. Coelli (1995). “A Model for Technical Inefficiency Effects in a Stochastic Frontier Production Function for Panel Data.” Empirical Economics 20 (2), $325-332$.

Coelli, T. (1996). “A Guide to FRONTIER Version 4.1: A Computer Program for Stochastic Frontier Production and Cost Function Estimation." CEPA Working Paper 96/07, Department of Econometrics, Armindale, New South Wales, Australia.

Crew, M. and P. Kleindorfer (1986). The Economics of Public Utility Regulation. Cambridge: MIT Press.

Crew, M. and P. Kleindorfer (2002). "Regulatory Economics: Twenty Years of Progress?", Journal of Regulatory Economics 21 (January), 5-22. 
Dussan, M (1996). "Electric Power Sector Reform in Latin America and the Caribbean.” Working Papers Series IFM-104.

Espinasa, R. (2001). "Marco Institucional de los Sectores Electricidad y Telecomunicaciones en América Latina." Research Department, Inter-American Development Bank.

Fischer, R. and P. Serra (2000). "Regulating the Electricity Sector in Latin America.” Economia (Fall), 155-218.

Kodde, D. and F. Palm (1986). "Wald Criteria for Jointly Testing Equality and Inequality Restrictions.” Econometrica 54 (5), 1243-1248.

Kridel, D., D. Sappington, and D. Weisman (1996). "The Effects of Incentive Regulation in the Telecommunications Industry: A Survey.” Journal of Regulatory Economics 9 (3), 269-306.

Kumbhakar, S. and L. Hjalmarsson (1998). "Relative Performance of Public and Private Ownership under Yardstick Competition: Electricity Retail Distribution.” European Economic Review 42 (1), 97-122.

Laffont, J. and J. Tirole (1993). A Theory of Incentives in Procurement and Regulation. MIT Press.

Meeusen, W. and J. van den Broeck (1977). "Efficiency Estimation from CobbDouglas Production Functions with Composed Error." International Economic Review 18 (2), 435-444.

Millan, J., E. Lora and A. Micco (2001). Sustainability of the Electricity Sector Reforms in Latin America. Research Department, Inter-American Development Bank. 
Rudnick, H. (1998). "Restructuring in South America - Successes and Failures." Power Economics Restructuring Review (June), 37-39.

Rudnick, H. and J. Zolezzi (2001). "Electric Sector Deregulation and Restructuring in Latin America: Lessons to be Learnt and Possible Ways Forward." IEE Proceedings $148(2), 180-184$.

Sappington, D. (1994). "Designing Incentive Regulation.” Review of Industrial Organization 9 (3), 245-272.

Vogelsang, I. (2002). "Incentive Regulation and Competition in Public Utility Markets: A 20-year Perspective.” Journal of Regulatory Economics 22 (July), 5-27. 


\section{Appendix}

In this appendix we present the data used in the empirical analysis. Before that, we briefly describe the main characteristics of the Latin American electricity sector and of the reforms that have taken place in the sector in the past 20 years.

\section{Latin American electricity distribution sector}

The Latin American electricity market has undergone a major transformation over the past 20 years. Reform in the region started in Chile with the privatization of major electric utilities between 1986 and 1989. Argentina followed Chile's example in 1992; shortly thereafter Bolivia, Colombia, and Peru followed suit. During the second half of the 1990s, Panama, El Salvador, Guatemala, Nicaragua, Honduras, and Brazil also adopted reforms. The main missing players in the process of transforming the electricity sectors have been Costa Rica, Ecuador, Mexico, Paraguay, Uruguay, and Venezuela, although Costa Rica, Ecuador, Mexico, and Venezuela recently initiated actions toward restructuring.

The diversity in the size of countries and power demand in the region—Brazil has a population of 160 million and an installed capacity of $58000 \mathrm{MW}$, while Honduras has 4.4 million people and $396 \mathrm{MW}$ - but all have followed similar paths for reforms. The reform processes in the region have been based on a central change in the paradigm for the electrical business. The paradigm has evolved from a stated-owned, vertically integrated electricity monopoly, to one in which different economic characteristics are recognized in the generation, transmission, and distribution stages. Competition among private operators is established in generation, with the State regulating transmission and distribution activities. 
As shown in Table A.1, however, in many Latin American countries the state still controls sizeable amounts of the generation, transmission, and distribution segments. ${ }^{13}$

Table A.1: Share of private sector participa tion in selected countries (in percent)

\begin{tabular}{c|ccc}
\hline & Generation & Transmission & Distribution \\
\hline Argentina & 60 & 100 & 70 \\
Bolivia & 90 & 90 & 90 \\
Brazil & 30 & 10 & 60 \\
Chile & 90 & 90 & 90 \\
Colombia & 70 & 10 & 50 \\
Costa Rica & 10 & 0 & 10 \\
Dominican Republic & 60 & 0 & 50 \\
Ecuador & 20 & 0 & 30 \\
El Salvador & 40 & 0 & 100 \\
Guatemala & 50 & 0 & 100 \\
Mexico & 10 & 0 & 0 \\
Paraguay & 0 & 0 & 0 \\
Peru & 60 & 20 & 80 \\
Uruguay & 0 & 0 & 0 \\
Venezuela & 20 & 10 & 40 \\
\hline
\end{tabular}

Source: Espinasa (2001).

The average percentages of private participation are roughly $41 \%, 22 \%$, and $51 \%$ for generation, transmission, and distribution—with a much lower variance for generation than for the other segments of the business. Generation has remained fully public only in Paraguay and Uruguay while transmission is mostly private only in Argentina, Bolivia, and Chile. The largest diversity of organizational arrangements is found in distribution; the distribution activity has remained fully public in three countries (Mexico, Paraguay, and Uruguay) and it has been fully transferred to the private sector in two countries (El Salvador and Guatemala). I most of the countries in the region public and private operators share the distribution market. From the viewpoint of efficiency concerns, this diversity is useful since it allows some degree of competition by comparison, and it generates enough diversity in the sample to allow an assessment of the impact of reform on the efficiency levels of the operators.

\footnotetext{
${ }^{13}$ For a description of the reforms in the region, see Dussan (1996); Rudnick (1998); Fischer and Serra (2000); Espinasa (2001); Millan, Lora, and Micco (2001); Rudnick and Zolezzi (2001).
} 
Table A.2 lists the type of regulatory regime by country.

Table A.2: Regulatory regimes in selected countries

\begin{tabular}{c|c}
\hline & Electricity distribution \\
\hline Argentina & Price cap \\
Bolivia & Hybrid \\
Brazil & Price cap \\
Chile & Hybrid \\
Colombia & Price cap \\
Costa Rica & Rate of return \\
Ecuador & Hybrid \\
El Salvador & Hybrid \\
Mexico & Rate of return \\
Paraguay & Rate of return \\
Panama & Price cap \\
Peru & Hybrid \\
Uruguay & Rate of return \\
Venezuela & Rate of return \\
\hline Source: Espinasa $(2001)$ &
\end{tabular}

About a third of the countries in the region have adopted a price-cap scheme while another third rely on rate of return regulation. The last third has adopted hybrid regimes in which some cost changes are automatically passed through to tariffs. This is clearly a very rough classification of the regulatory regimes since the incentive for improvements in efficiency are strongly correlated with the specific design of the overall regulatory regime. In the case of hybrid regimes, for instance, the larger the share of costs enjoying an automatic pass-through rule, the closer the regime is to cost-plus and hence the lower the expected incentive to minimize costs. The classification is, however, useful enough to allow an explicit modelling of the influence of broad categories of regulation on the efficiency of the operators.

\section{The database}

Data on firms was collected from several sources. Data for South America in the period 1994-2000 was mostly compiled from CIER (commission that co-ordinates the different participants in the electricity sector in South America) reports: Datos Estadísticos. Empresas Eléctricas. Año 1994; Datos Estadísticos. Empresas Eléctricas. 
Años 1995-1996-1997; Información Económica y Técnica de Empresas Eléctricas. Datos 1998-1999; and Información Económica y Técnica de Empresas Eléctricas. Datos 2000. Data for Argentina in the year 2001 was provided by ADEERA (an institution that coordinates firms in the Argentine electricity sector). Other South American data corresponding to the year 2001 were obtained from firms' balance sheets. Data for Costa Rica was provided by the energy department of ARESEP (regulator of public services in Costa Rica). Data for Panama was obtained from the firm's balance sheet. Data for Mexico was provided by CFE (federal commission of electricity). Data for El Salvador was provided by SIGET (regulator of the electricity and telecommunication sectors in El Salvador).

Most of the data was checked using information provided by regulators and governmental agencies. In this respect, we used information provided by ADEERA, ENRE (regulator of the electricity sector in Argentina), ANEEL (national agency of electrical energy, Brazil), CONELEC (governmental agency in charge of the electricity sector in Ecuador), CTE (commission in charge of energy tariffs in Peru), and URSEA (regulator of the service of water and energy in Uruguay).

The database includes the following variables:

- sales to final customers, in GWh. Sales to final customers were calculated as total sales minus sales to other electric companies, in order to isolate the distribution activity in the case of integrated firms;

- number of final customers;

- service area, in square kilometres;

- residential sales' share, a proxy for demand structure; 
- total distribution lines, in kilometres (including high and low voltage power lines);

- total transformer capacity, in mega-volt-amper, MVA;

- number of employees. Data on number of employees includes information on part-time and full-time employees. Part-time employees were counted as halftime employees. In vertically integrated firms there is information on the number of employees employed by each department: generation, transmission, distribution, billing and collection, and administrative. For these firms, the number of employees of firm $j$ was calculated as follows: $l_{j}=l_{j j}+l_{2 j}+\left[\sum_{k=1}^{2} l_{k j} / \sum_{k=1}^{4} l_{k j}\right] l_{5 j}$, where $l_{1 j}=$ distribution (proper); $l_{2 j}=$ billing and collection; $l_{3 j}=$ generation; $l_{4 j}=$ transmission; and $l_{5 j}=$ administrative and general.

The sample is representative of the electricity distribution sector in the region. It covers 110 firms from the following countries: Argentina (22 firms supplying electricity to $70 \%$ of the total number of customers in the country), Bolivia $(2,30 \%)$, Brazil (37, 70\%), Chile (2, 19\%), Colombia (5, 34\%), Costa Rica (3, 80\%), Ecuador (12, 60\%), El Salvador (4, 95\%), Mexico (1, 79\%), Panama (1, 62\%), Paraguay (1, 100\%), Peru (11, 97\%), Uruguay $(1,100 \%)$, and Venezuela $(8,92 \%)$.

In the empirical applications we also use information on GNP per capita. Purchasing power parity (PPP) estimates of GNP per capita were obtained from the World Bank database. We use PPP figures in order to correct for international differences in relative prices (for details, see World Development Report technical notes). 
wb14570

N:IAntonioltena2ltena1 paperstrossilHave Consumers Benefited from the Reforms.doc

September 22, 2004 3:25 PM 